M. Birski ${ }^{1, *}$, D. Dabrowski ${ }^{2,3}$, M. Peryt ${ }^{2,3}$, K. Roslon ${ }^{2,3}$, M. Bielewicz ${ }^{3,4}$

\title{
NETWORK ANALYZER USED IN MPD SLOW CONTROL SYSTEM AUTOMATION
}

Submitted to "Particles and Nuclei, Letters"

${ }^{1}$ University of Wroclaw, Wroclaw, Poland

${ }^{2}$ Warsaw University of Technology, Warsaw

${ }^{3}$ Joint Institute for Nuclear Research, Dubna

${ }^{4}$ National Centre for Nuclear Research, Warsaw

*E-mail: birski@gmail.com 
Бирски М. и др.

Сетевой анализатор, используемый в системе медленного контроля детектора MPD

Многоцелевой детектор MPD является частью проекта NICA, реализуемого в Объединенном институте ядерных исследований (Дубна). Наряду с прочими подобными системами, система медленного контроля SCS (Slow Control System) предназначена для осуществления управления и контроля параметров детекторов, отличающихся относительно низкой частотой дискретизации и не зависящих от эксперимента. В данной работе описывается сетевой анализатор, используемый в стойках питания детектора MPD, а также программа автоматизации, разработанная в LabVIEW. Данное устройство анализирует основные параметры сети питания, например, ток, мощность или напряжение каждой из 64 стоек. Стойка состоит из нескольких подсистем управления, таких как контроль температуры, газа и т.д. Чтобы сделать эти подсистемы когерентными с точки зрения передачи данных, была использована среда LabVIEW. Программа автоматизации сетевого анализатора LabVIEW является частью целостной согласованной системы, содержащей множество субВП, соединенных кластерными каналами.

Работа выполнена в Лаборатории физики высоких энергий им. В. И. Векслера и А. М. Балдина ОИЯИ.

Препринт Объединенного института ядерных исследований. Дубна, 2017

Birski M. et al.

E13-2017-84

Network Analyzer Used in MPD Slow Control System Automation

Multi-Purpose Detector (MPD) is a part of the NICA project at JINR (Dubna). Among many control systems, Slow Control System (SCS) is dedicated to handle and control the parameters of detectors which vary with relatively slow sample rate and do not depend on the experiment. This paper describes the network analyzer used in the MPD supply racks as well as automation program made in LabVIEW. This device analyzes the main supply network parameters, e.g., current, power or voltage of each of 64 supply racks. Rack consists of many control subsystems, e.g., temperature control, gas control, and many others. In order to make these subsystems coherent in terms of data transmission, LabVIEW environment has been used. The network analyzer LabVIEW automation program is one part of the whole coherent automation system, containing a variety of subVI's connected by cluster links.

The investigation has been performed at the Veksler and Baldin Laboratory of High Energy Physics, JINR. 


\section{INTRODUCTION}

The main goal of the NICA project at JINR (Dubna) is to study heavy ion and polarized proton and deuteron collisions [1]. It comprises the following subprojects: upgrade of the existing superconducting synchrotron Nuclotron, the Baryonic Matter at Nuclotron (BM@N) experiment with ion beams extracted from the modernized Nuclotron, and an experiment with the Multi-Purpose Detector (MPD) at the first (right-hand collider ring) interaction point (IP) of NICA with a primary goal to study heavy ion collisions. MPD consists of many subdetectors, e.g., Time Projection Chamber (TPC), Inner Tracker (IT), Time-of-Flight (TOF) system, and Electromagnetic Calorimeter (ECal). Detector control system can be roughly divided into two parts: readout system, which is responsible for data acquisition and gives information about the investigated phenomena, and system which controls physical parameters of the detector, e.g., currents and voltages. The second one is usually called SCS (Slow Control System). SCS is responsible for maintenance and control the detector parameters which are restricted for proper work of the detector. Parameters like temperature of gas chamber or supply source voltages and currents do not have to be sampled with relatively high frequency, as it occurs in data acquisition, thus this system is called Slow Control. SCS is a set of electronic circuits (hardware), implemented software, as well as technical documentation (bookware) of the experiment control system.

\section{MPD SLOW CONTROL SYSTEM}

Slow Control System for MPD is currently under construction and consists of many different hardware and software branches. MPD is supplied with 64 racks, and each rack comprises different modules. In this paper, electrical network analyzer LUMEL N43 and dedicated LabVIEW software are described. LUMEL $\mathrm{N} 43$ is the first device in the rack which is connected to the power network (see Fig. 1).

LUMEL N43 is connected with the control system by RS-485 serial port, and data transmission takes place through RS bus. Network analyzer gives a lot of information about electrical network, measured as well as calculated one. Data are located in the registers. In order to get data from the network analyzer, 


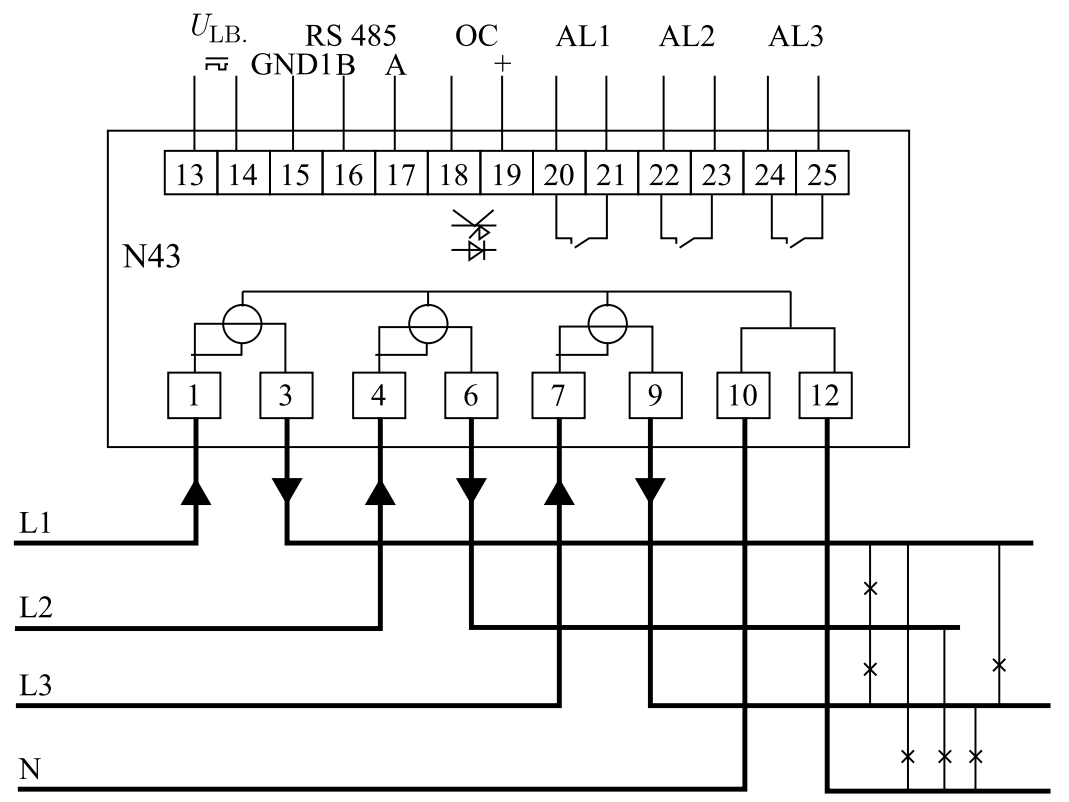

Fig. 1. LUMEL N43 network analyzer serial connection between power source and rack

LabVIEW sends a query and waits for an answer. In Fig. 2, LabVIEW code is shown. The code is executed from the left to the right side. First of all, before the while loop starts, modbus protocol parameterization (New Serial Master) takes place. Inside the while loop data processing is being realized. Waiting time was set up for $600 \mathrm{~ms}$, which is technically enough for SCS. In each iteration, seven most important parameters are taken from registers for each phase (L1, L2, L3) and transmitted like arrays through the code.

For MPD SCS needs, the following parameters were taken into account: voltage $(\mathrm{V})$, current $(\mathrm{A})$, true power $(\mathrm{W})$, apparent power (VA), reactive power (VAR), power coefficient, and phase tangent. Other two variables are vector current in $\mathrm{N}$ wire and frequency. Data are depicted in the front panel (see Fig. 3). Front panel is a representation of Graphical User Interface (GUI) in LabVIEW terminology.

The most important idea is data clustering. All parameters are packed into clusters and transfered by the shift register during each iteration. Data clustering allows data transfer among other VI's during one session. This idea also works for error transmission and handling. Due to the fact that data can be moved from one VI to another, a lot of applications appear. This program compares instantaneous value of current with maximum values given in advance. This is very important because, for instance, if current is exceeded, devices located in the rack can break 
a

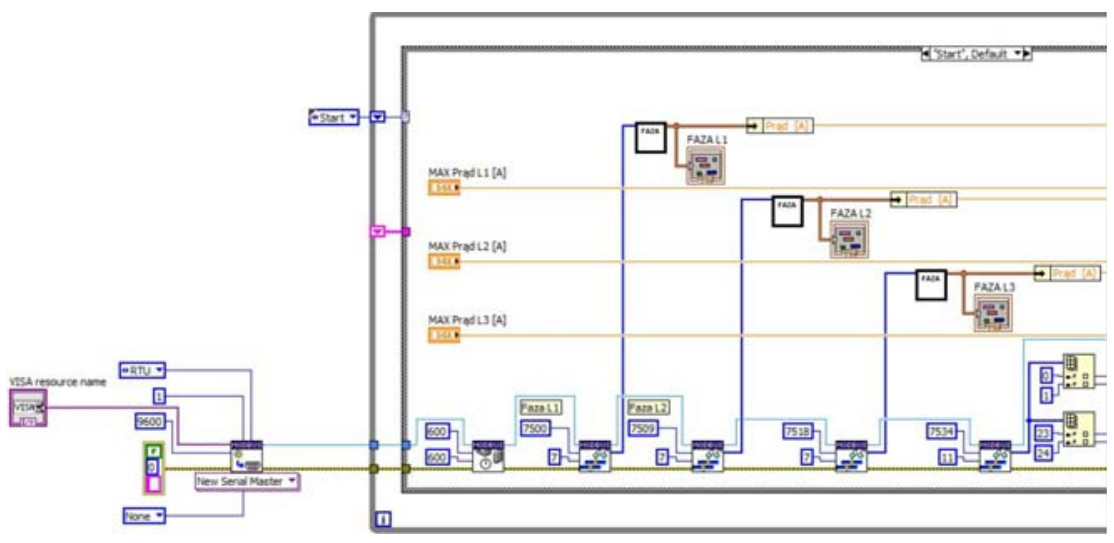

b

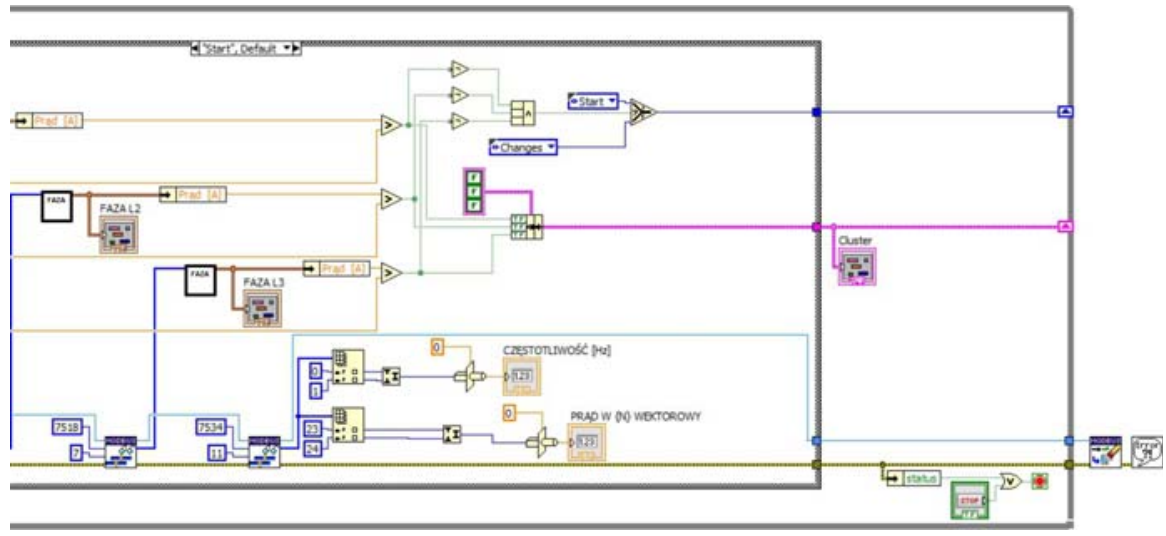

Fig. 2. Network analyzer LabVIEW code — parts A $(a)$ and B $(b)$

down or even burn out. Technically this option stands for safety and maintenance of the required values. Part of the code responsible for current comparison is also shown in Fig. 2. Instantaneous current value is being compared with the value given in advance. When the current exceeds maximum value, the program builds boolean cluster with TRUE value. This cluster is transmitted through the shift register during each iteration and can be also transmitted to another VI. Another VI can be in charge of safety and can turn off other devices which could break down due to increased current value. Program is made in elastic way, so any needed values can be compared and sent to other VI's. This is a big advantage of LabVIEW data transmission scheme. If there is any registered unneeded current 


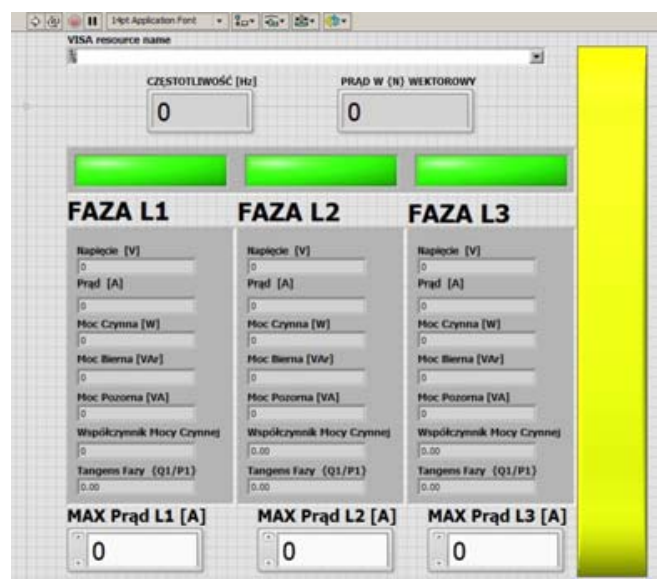

Fig. 3. Network analyzer LabVIEW front panel (GUI). Green lights become red when the values are exceeded

value, program moves the whole process to the "changes" case, where another sophisticated process can be run.

\section{CONCLUSIONS}

This paper describes LabVIEW code for MPD supplying rack network analyzer. Data transmission takes place through RS-485 bus. Data clustering is a leading idea of MPD SCS LabVIEW codes. Clustered data transmission through shift registers allows fast and elastic connection between subVI's having different duties in the control system. The presented program has been made in order to give details about supply network parameters and can be treated as a portable subVI in complex control system.

\section{REFERENCES}

1. Kekelidze V. D. et al. // PoS (ICHEP2012). 2013. P. 411.

Received on November 24, 2017. 
Редактор Е. И. Крупко

Подписано в печать 12.02.2018.

Формат $60 \times 90 / 16$. Бумага офсетная. Печать офсетная.

Усл. печ. л. 0,44. Уч.-изд. л. 0,59. Тираж 215 экз. Заказ № 59339.

Издательский отдел Объединенного института ядерных исследований 141980 , г. Дубна, Московская обл., ул. Жолио-Кюри, 6.

E-mail: publish@jinr.ru

www.jinr.ru/publish/ 